\title{
The effects of upper and lower limb exercise on the microvascular reactivity in limited cutaneous systemic sclerosis patients
}

\author{
A. Mitropoulos ${ }^{1}$, A. Gumber ${ }^{2}$, H. Crank ${ }^{1}$, M. Akil ${ }^{3}$ and M. Klonizakis ${ }^{1 *}$ (ID
}

\begin{abstract}
Background: Aerobic exercise in general and high-intensity interval training (HIIT) specifically is known to improve vascular function in a range of clinical conditions. HIIT in particular has demonstrated improvements in clinical outcomes, in conditions that have a strong macroangiopathic component. Nevertheless, the effect of HIIT on microcirculation in systemic sclerosis (SSc) patients is yet to be investigated. Therefore, the purpose of the study was to compare the effects of two HIIT protocols (cycle and arm cranking) on the microcirculation of the digital area in SSc patients.
\end{abstract}

Methods: Thirty-four limited cutaneous SSc patients (65.3 \pm 11.6 years old) were randomly allocated in three groups (cycling, arm cranking and control group). The exercise groups underwent a 12- week exercise program twice per week. All patients performed the baseline and post-exercise intervention measurements where physical fitness, functional ability, transcutaneous oxygen tension $\left(\Delta \mathrm{T}_{\mathrm{c}} \mathrm{O}_{2}\right)$, body composition and quality of life were assessed. Endothelial-dependent as well as -independent vasodilation were assessed in the middle and index fingers using LDF and incremental doses of acetylcholine (ACh) and sodium nitroprusside (SNP). Cutaneous flux data were expressed as cutaneous vascular conductance (CVC).

Results: Peak oxygen uptake increased in both exercise groups $(p<0.01, \mathrm{~d}=1.36) . \Delta \mathrm{T}_{\mathrm{c}} \mathrm{O}_{2}$ demonstrated an increase in the arm-cranking group only, with a large effect, but not found statistically significant, $(p=0.59, \mathrm{~d}=0.93)$. Endothelial-dependent vasodilation improvement was greater in the arm-cranking $(p<0.05, d=1.07)$ in comparison to other groups. Both exercise groups improved life satisfaction $(p<0.001)$ as well as reduced discomfort and pain due to Raynaud's phenomenon $(p<0.05)$. Arm cranking seems to be the preferred mode of exercise for study participants as compared to cycling $(p<0.05)$. No changes were observed in the body composition or the functional ability in both exercise groups.

Conclusions: Our results suggest that arm cranking has the potential to improve the microvascular endothelial function in SSc patients. Also notably, our recommended training dose (e.g., a 12-week HIIT program, twice per week), appeared to be sufficient and tolerable for this population. Future research should focus on exploring the feasibility of a combined exercise such as aerobic and resistance training by assessing individual's experience and the quality of life in SSc patients.

Trial registration: ClinicalTrials.gov (NCT number): NCT03058887, February 23, 2017.

Keywords: High-intensity interval training, Vascular function, Quality of life

\footnotetext{
* Correspondence: m.klonizakis@shu.ac.uk

${ }^{1}$ Centre for Sport and Exercise Science, Collegiate Campus, Sheffield Hallam

University, Collegiate Crescent, Sheffield S10 2BP, UK

Full list of author information is available at the end of the article
}

(c) The Author(s). 2018 Open Access This article is distributed under the terms of the Creative Commons Attribution 4.0 International License (http://creativecommons.org/licenses/by/4.0/), which permits unrestricted use, distribution, and reproduction in any medium, provided you give appropriate credit to the original author(s) and the source, provide a link to the Creative Commons license, and indicate if changes were made. The Creative Commons Public Domain Dedication waiver (http://creativecommons.org/publicdomain/zero/1.0/) applies to the data made available in this article, unless otherwise stated. 


\section{Background}

Systemic sclerosis (SSc) is an idiopathic systemic autoimmune disease characterized by an ongoing cutaneous and visceral fibrosis, fibroproliferative vasculopathy and immunologic abnormalities [1-4]. The vascular element has an important role in the SSc pathophysiology from early onset to late complications (e.g., pulmonary arterial hypertension and kidney disease). SSc can be distinguished in either limited cutaneous scleroderma (lcSSc) with skin involvement mainly limited to the hands and face; or diffuse cutaneous scleroderma (dcSSc) with skin involvement proximal to the elbows and knees [5]. Blood vessels are directly affected by SSc, as manifested by the diverse clinical complications that take place from the initiation to the propagation of the disease, and have important ramifications on the quality of life (QoL) of patients.

Raynaud's phenomenon (RP) precedes other clinical manifestations and is observed in over $95 \%$ of SSc patients [6]. Evidently, RP is triggered by endothelial injuries in association with dysregulations in the vascular tone [7]. In addition to the imbalance of vascular tone, $\mathrm{RP}$ is also associated with structural vascular alterations in small- and medium-sized arteries leading to luminal narrowing. As a result, the blood vessels are unable to compensate for the impairment of blood flow during severe RP attacks and this leads to the so-called ischaemia-reperfusion reactions. These vascular complications may progress to gangrene and digital amputation [8]. Notably, SSc has the highest case-specific mortality of any rheumatic disease being also associated with substantial morbidity [9].

Pharmacological agents (e.g., nifedipine) are commonly used as first-line approach. Although it can be effective and provide pain-relief to patients, the shortterm (e.g., oedema, headaches, heart palpitations, dizziness and constipation) and long-term (e.g., heart dysfunction, increased cardiovascular risk) side effects of the medical treatment should also be considered as well as the financial cost of treatment. Therefore, alternative approaches with less side effects and cost implications are warranted $[10,11]$, with a view to reducing dependency on medication.

Exercise in general and high-intensity interval training (HIIT) specifically could be a useful adjunct therapy for this population. HIIT has come to prominence over the last few years for its effectiveness in inducing greater improvements in vascular function than moderate-intensity continuous training in a number of clinical populations (e.g., heart failure, metabolic syndrome, obesity) [12]. Nevertheless, due to the variation in HIIT protocols, limited evidence exists to support which protocol would be the most effective in SSc patients, although the options are many, based on evidence from other patient populations. For example, a HIIT protocol with short intervals (30 s exercise/30 s passive recovery) may elicit more favourable patient-reported satisfaction/enjoyment levels compared to other longer duration exercise protocols [13]. In chronic heart failure patients, a short duration HIIT protocol (30 s exercise/30 s passive recovery) has demonstrated to be a well-tolerated, preferred protocol with a low perception of effort, patient comfort and with a longer time spent at higher percentage of peak oxygen uptake $\left(\dot{\mathrm{V}} \mathrm{O}_{2 \text { peak }}\right)$ than a longer duration HIIT protocol with active recovery phases [13]. Recent evidence supports this notion; when enjoyment levels in an overweight/obese cohort were examined after a short HIIT protocol and demonstrated that performing a HIIT protocol on a cycle ergometer present on an average 4.5 rating on a 7-point scale [14].

Although we know the potential of HIIT in improving both the micro-and the macro- vascular function in several clinical populations such as heart failure [15] and cardiometabolic disease [16] by using the treadmill and cycle ergometer as modes of exercise, no evidence exists about the mode of exercise that would be more effective on digital microcirculation where the RP attacks are present, such as in SSc patients. Assumptions could be made that utilising an upper-body exercise would potentially be more beneficial for the digital microcirculation rather than lower-body exercise where the working muscles promote the blood flow in the lower limbs. Hence, the effects that may occur by the upper- and lower-limb exercise on digital microcirculation in SSc patients should be examined.

We will attempt to bridge the knowledge gap by assessing the effects of a supervised and individually-tailored exercise programme based on arm cranking (ACE) and cycle ergometry (CE) on microvascular reactivity, aerobic capacity, exercise tolerance and enjoyment levels, as well as on QoL in SSc patients.

\section{Methods \\ Patients}

We recruited 34 patients (31 women, 3 men) with lcSSc, defined as per the American College of Rheumatology and European League Against Rheumatism criteria [17], with disease duration between 1 to 10 years. All participants were able to undertake exercise. Patients with pulmonary arterial hypertension, interstitial lung disease, those diagnosed with another inflammatory condition and/ or presenting myositis with proximal muscle weakness were excluded. Moreover, patients with New York Heart Association class 3 or 4, smokers or people who stopped smoking within 4 weeks of screening and women who were pregnant were also not permitted to participate. Eligible patients were recruited from the Rheumatology Department of the Royal Hallamshire 
Hospital in Sheffield. All patients provided written consent to participate. The regional health research ethics committee for clinical studies approved the protocol. Patients were randomly allocated between the ACE $(n=$ $11), \mathrm{CE}(n=11)$ and control $(n=12)$ groups. All the preand post-intervention tests were performed at the same time of the day to minimize intra-day variability.

\section{Procedures}

Baseline assessments, undertaken at first visit, included $\dot{\mathrm{V}}{ }_{2 \text { peak, }}$, anthropometry, functional ability, microvascular reactivity and QoL. $\dot{\mathrm{V}} \mathrm{O}_{2 \text { peak }}$ test was performed either on an arm crank ergometer (ACE group) or on a cycle ergometer (CE and control group). Thereafter, patients were randomly allocated to three groups (ACE, CE and control group). The exercise groups (ACE and $\mathrm{CE}$ ) performed a 12-week exercise programme and the control group did not perform any type of physical activity. All groups were followed up after a 12-week period performing the same measurements as in the baseline. Figure 1 depicts the study's procedures.

\section{Anthropometry}

The participant's stature was measured using a Hite-Rite Precision Mechanical Stadiometer. Body weight (kg), body mass index (BMI), fat mass $(\mathrm{kg})$ and lean body mass $(\mathrm{kg})$ segmented in upper and lower limbs were assessed by using bio-electrical impedance analysis (In Body 720, Seoul, Korea). Patients' demographic characteristics are illustrated in Table 1.

\section{Peak oxygen uptake test}

During the cardiopulmonary tests gas exchange was collected and analysed by an online breath-by-breath analysis system (Ultima $^{\mathrm{Tx}}$, Medical Graphics, Gloucester, UK). Heart rate (HR) was continuously monitored using a Polar heart rate monitor (Polar FS1, Polar Electro, Kemple, Finland) and blood pressure was assessed by the researcher using a manual sphygmomanometer (DuraShock DS54, Welch Allyn, Beaverton, OR, USA) and a stethoscope (Littman Classic II, $3 \mathrm{M}$, Maplewood, MI, USA). Rating of perceived exertion (RPE) was recorded during the last $10 \mathrm{~s}$ of every minute during the exercise test until volitional exhaustion using Borg's scale [18] 6-20 point. Peak power output (PPO) and test duration was measured in both tests. $\dot{\mathrm{V}} \mathrm{O}_{2 \text { peak }}$ defined as the average oxygen consumption was recorded from expiratory samples during the final $30 \mathrm{~s}$ of exercise.

\section{Arm crank test}

The arm crank ergometer (Lode BV, Groningen, Netherlands) was adjusted to ensure alignment between

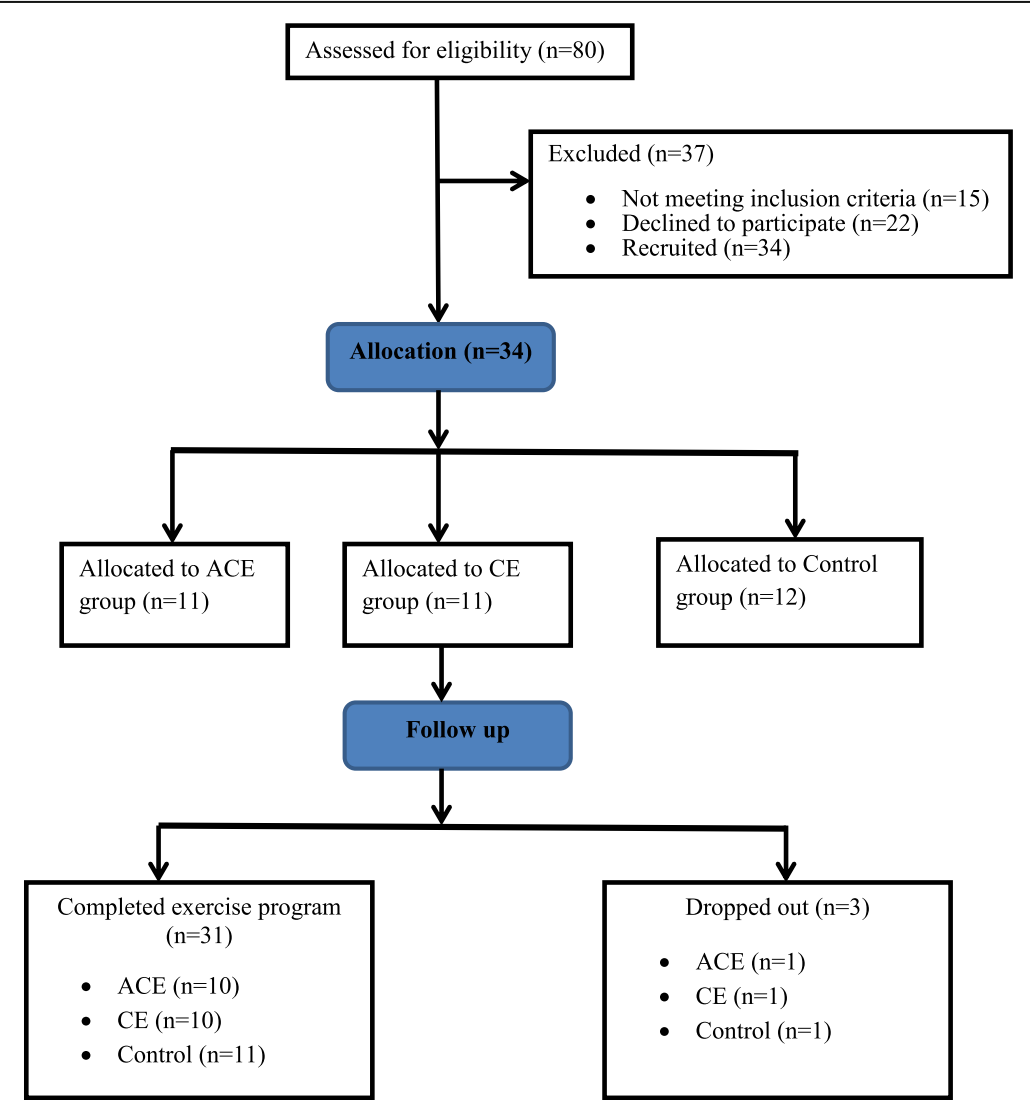

Fig. 1 CONSORT flow diagram. ACE arm crank ergometer, CE cycle ergometer 
Table 1 Demographic data (means \pm SD)

\begin{tabular}{llll}
\hline & Baseline ACE & Baseline CE & Baseline Control \\
\hline Age (years) & $69.1 \pm 9.7$ & $65.1 \pm 10$ & $62.2 \pm 14.3$ \\
Body weight $(\mathrm{kg})$ & $69 \pm 15.8$ & $66 \pm 9.7$ & $73.2 \pm 14.8$ \\
Body mass index $\left(\mathrm{kg} / \mathrm{m}^{2)}\right.$ & $25.6 \pm 4.8$ & $24.5 \pm 3.6$ & $27.3 \pm 4.0$ \\
Stature $(\mathrm{cm})$ & $163.7 \pm 9.1$ & $164.4 \pm 7.9$ & $163.4 \pm 6.7$ \\
Disease duration (yrs) & $7.8 \pm 2.3$ & $7.7 \pm 2.1$ & $6.3 \pm 2.0$ \\
Digital ulcers (treatment iloprost infusion) & $0 / 10$ & $0 / 10$ & $4 / 11$ \\
Raynaud's treatment & $6 / 10$ & $5 / 10$ & $8 / 10$ \\
Nifedipine & $4 / 10$ & $4 / 10$ & $4 / 10$ \\
Sildenafil & $2 / 10$ & $1 / 10$ & $4 / 10$ \\
Blood pressure treatment & $6 / 10$ & $4 / 10$ & $4 / 10$ \\
Candesartan & $4 / 10$ & $0 / 10$ & $1 / 10$ \\
Ramipril & $2 / 10$ & $4 / 10$ & $3 / 10$ \\
\hline
\end{tabular}

ACE arm crank ergometer, $C E$ cycle ergometer

the ergometer's crankshaft and the centre of the patient's glenohumeral joint. Patients' sitting position was set up to ensure that the elbows were slightly bent when the arm was outstretched. Patients were instructed to maintain their feet flat on the floor at all times. Due to differences in gender power capabilities, two separate protocols were instructed for men and women. Men commenced at a workload of $30 \mathrm{~W}$ and women at $20 \mathrm{~W}$. In both protocols the crank rate was maintained at $70 \mathrm{rev} \min ^{-1}[19,20]$ and power requirements increased as a linear ramp at a rate of $10 \mathrm{~W} / \mathrm{min}$ and $6 \mathrm{~W} / \mathrm{min}$ for men and women, respectively [20]. The test commenced with $3 \mathrm{~min}$ resting and then $3 \mathrm{~min}$ of warm-up (unloaded cranking). RPE $\geq 18$ and/or inability

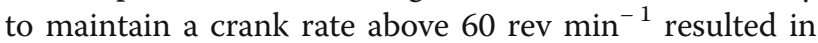
the termination of the test. After the exercise termination an unloaded bout of 2-3 min exercise at a crank rate below $50 \mathrm{rev} \mathrm{min}^{-1}$ followed allowing for an active recovery period.

\section{Cycle ergometer test}

The cycle ergometer test was performed on an electromagnetic cycle ergometer (Lode Excalibur, Groningen, Netherlands). The test commenced with a $3 \mathrm{~min}$ resting period followed by $3 \mathrm{~min}$ of unloaded pedalling. Participants were requested to maintain a cycle rate of $60 \mathrm{rev} \mathrm{min}^{-1}$ during the exercise test. The starting load and the concomitant increments were individually calculated according to participants' estimated physical fitness and Wasserman's eqs. [21]. $R P E \geq 18$ and/or inability to maintain a crank rate above $40-45 \mathrm{rev} \mathrm{min}^{-1}$ resulted in the termination of the test. Following the exercise test $2-3 \mathrm{~min}$ of unloaded pedalling was performed to allow for an active recovery period.

\section{Exercise program}

Patients undertook twice-weekly supervised exercise sessions at the Centre of Sport and Exercise Science at Sheffield Hallam University. Each session started with a 5 min warm-up on an arm crank or cycle ergometer depending on the group (involving light aerobic exercise and gentle range of motion exercises). This was followed by HIIT for $30 \mathrm{~s}$ at $100 \%$ of PPO interspersed by $30 \mathrm{~s}$ passive recovery for a total of $30 \mathrm{~min}$ (Fig. 2). At the end of the session patients undertook a 5 min cool-down period, involving lower- and upper-limb light intensity aerobic exercise and light stretching. Patients were wearing heart rate monitors throughout the exercise sessions. Heart rate and RPE and effect (see below) were assessed at regular intervals throughout the supervised exercise session.

\section{Functional ability test}

The functional ability was assessed through a six-minute walking test (6MWT). Although the $6 \mathrm{MWT}$ lacks organ specificity in SSc, it can provide a valuable outcome parameter and thus, is suggested as a regular assessment in this clinical condition [22]. Patients were instructed to walk as far as possible back and forth on a $10 \mathrm{~m}$ corridor for $6 \mathrm{~min}$. They were also instructed to slow down, stop and/or rest as necessary if they got out of breath or became exhausted, but to resume walking as soon as they felt able to. The laps and the total walking distance were recorded on a worksheet.

\section{Microvascular reactivity}

Microvascular function was assessed by laser Doppler Fluximtery and Iontophoresis technique in a temperature-controlled room $\left(22-24{ }^{\circ} \mathrm{C}\right)$. Laser Doppler fluximetry (LDF) electrodes were attached to the dorsal aspect of the reference fingers for acetylcholine (ACh) 


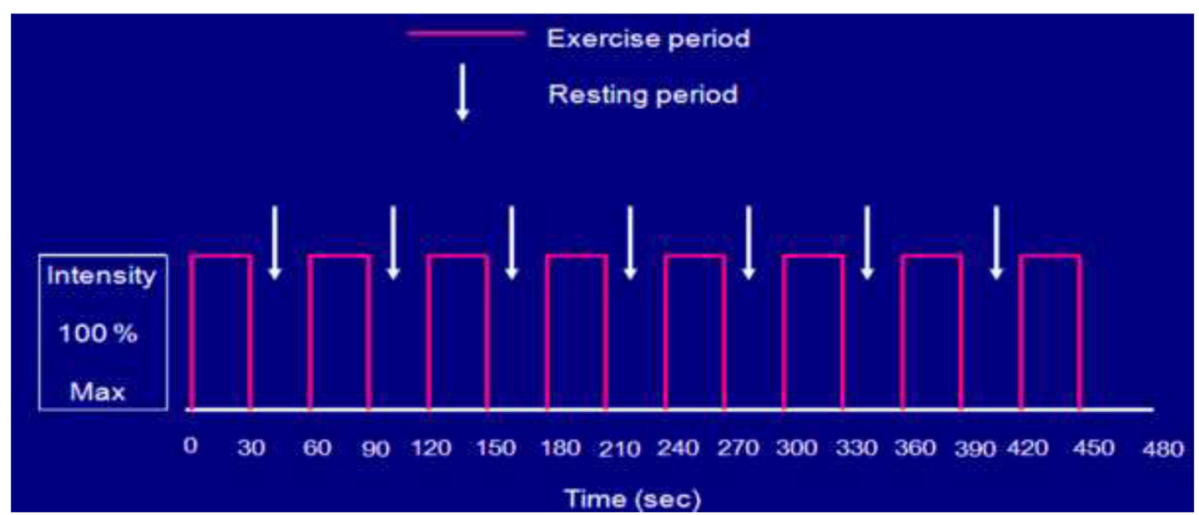

Fig. 2 Schematic training protocol

and sodium nitroprusside (SNP) administration. These were used as indicators of the changes occurring in the endothelial-dependent and -independent vasodilatory function. Heart rate (Sports Tester, Polar, Finland) and blood pressure of the brachial artery (left arm; Dinamap Dash 2500, GE Healthcare, Chicago, IL, USA) were monitored at 5-min intervals throughout the protocol. The two drug delivery electrodes (PF383; Perimed AB, Jarfalla, Sweden) were positioned over healthy-looking skin, approximately $4 \mathrm{~cm}$ apart with one containing $100 \mu \mathrm{L}$ of 1\% ACh (Miochol-E, Novartis, Stein, Switzerland.) and the other $80 \mu \mathrm{L}$ of $1 \%$ SNP (Nitroprussiat, Rottapharm, Monza, Italy). ACh was placed over the middle finger between the distal and proximal interphalangeal joints and SNP was placed over the index finger between the metacarpophalangeal and carpometacarpal joints. The incremental iontophoresis protocol for ACh and SNP delivery is described in Klonizakis et al., [23, 24].

\section{Transcutaneous oxygen pressure $\left(\mathrm{TcpO}_{2}\right)$}

$\mathrm{TcpO}_{2}$ measurements were performed during the cardiorespiratory tests using sensors that were non-invasively attached onto the skin and allowed to heat. The sensors induce skin blood capillaries dilatation through heat, which increases the blood flow and results in oxygen diffusion through the skin to the sensor. The sensor measures $\mathrm{TcpO}_{2}$ values inwardly through an electrochemical process.

Measurements were performed using the TINA TCM400 $\mathrm{TcpO}_{2}$ device (Radiometer, Copenhagen, Denmark). The temperature of the probe was set to 44 . $5{ }^{\circ} \mathrm{C}$ to allow maximal skin vasodilation, thereby decreasing the arterial to skin surface oxygen pressure gradient. Before the exercise test 15-20 min were allowed with the probe attached on the skin for stabilisation of $\mathrm{TcpO} 2$ value. After the test the $\mathrm{TcpO} 2$ values were automatically corrected according to a temperature of $37^{\circ} \mathrm{C}$ by the TINA device. The electrode was placed slightly below the right scapula on the back away from any bone.

Fixation rings were used to hold the probe attached to the skin and this was filled with two small drops of contact fluid before attachment to the sensor. The fluid was then heated causing the subsequent dilatation of the skin. The raw values of the patient's oxygen perfusion, obtained directly from TcpO2 device were defined (Table 2) as previously described in Wasilewski et al. [25].

\section{Quality of life}

The EQ-5D-5 L was the main outcome used to assess the patients' quality of life pre- and post-exercise intervention. The EQ-5D-5 L is a generic measure of health state by considering five key dimensions of daily living (mobility, self-care, ability to undertake usual activities, pain, anxiety/depression) [26]. Participants were asked to describe their level of health on each dimension using one of five levels: no problems, slight problems, moderate problems, severe problems, extreme problems. $\mathrm{Pa}$ tients were also asked about to rate their life satisfaction on a scale of zero to ten as well as to rate the RP pain during the last couple of weeks on one to five ascending grading: not at all, slightly, moderately, severely,

Table 2 Definitions of TcpO2 quantities

\begin{tabular}{|c|c|}
\hline TcpO2 quantity & Definition \\
\hline Baseline & $\begin{array}{l}\text { The arithmetic mean of maximum } \\
\text { TcpO2 } 2 \text { at rest. }\end{array}$ \\
\hline $\mathrm{TcpO}_{\max }$ & $\begin{array}{l}\text { The highest } \mathrm{TcpO} 2 \text { value recorded } \\
\text { every minute of exercise or at rest. }\end{array}$ \\
\hline $\begin{array}{l}\text { Maximum change from baseline } \\
\left(\Delta \mathrm{T} c \mathrm{OO} 2_{\text {max }}\right)\end{array}$ & $\begin{array}{l}\text { The outcome of the subtraction of } \\
\text { baseline from } \mathrm{TcpO} 2_{\text {max }} \text { : e.g. } \\
\mathrm{TcpO} 2_{\text {max }} \text { - baseline }\end{array}$ \\
\hline $\begin{array}{l}\text { Changes in transcutaneous } \\
\text { oxygen pressure }(\Delta \mathrm{TcpO} 2)\end{array}$ & $\begin{array}{l}\text { The average sum of the change from } \\
\text { baseline at rest and exercise period: } \\
\left.\left.\text { e.g. }(\Sigma) \Delta Y_{1} \ldots n\right) / n\right)=\Delta \mathrm{TcpO}_{2}\end{array}$ \\
\hline
\end{tabular}

$\triangle T \mathrm{TpO}_{2}$ transcutaneous oxygen tension 
extremely. Digital ulcers and hospitalization for iloprost infusion and amputations were also recorded.

\section{Exercise tolerance}

The exercise tolerance of HIIT was assessed through measures that were interpreted participants' perception regarding the exercise intensity, the effect (Additional file 1), the exercise task self-efficacy (Additional file 2), the intentions (Additional file 3) and the enjoyment (Additional file 4). The above data was collected at the first and last exercise session each month in order to examine several time points during the exercise intervention. Specifically, the questionnaires were repeated at the 1st, 8th, 16th, and 24th exercise sessions. The individual questionnaires and the time points that were incorporated during the exercise session are described in Jung et al. [27].

\section{Statistical analysis}

Data analysis was performed using SPSS software (version 23, IBM SPSS, Armonk, NY, USA) and is presented as mean $\pm \mathrm{SD}$. Normal distribution of the data and homogeneity of variances were tested using the ShapiroWilk and Levene's test, respectively. The comparison in the anthropometric, physiological and vascular characteristics among the three groups was done through a one-way ANOVA test. Independent t-tests and chisquared tests were also used to identify the differences between two groups. Effect sizes (Cohen's d) were calculated wherever the results were statistically significant with $0.2,0.5$, and 0.8 representing small, medium, and large effects respectively [28]. To compare the between group differences using a one-way ANOVA we adjusted the ACE values according to the physiological and anthropometrical responses of CE [29]. Statistical significance was set at $p \leq 0.05$.

\section{Results}

\section{Compliance and exercise intensity}

Compliance to the12-week exercise programme twice weekly was $92 \%$ and $88 \%$ for the ACE and CE group respectively, with one drop-out for each exercise group. No exercise-related complications were reported. The average percentage peak $\mathrm{HR}\left(\% \mathrm{HR}_{\text {peak }}\right)$ for each exercise session was $92.1 \% \pm 6.0$ for the ACE group and $90.8 \% \pm$ 7.5 for the CE group. The average rate of perceived exertion (RPE) and effect were $13 \pm 1$ and +3 (good) \pm 1 , respectively, for both exercise groups.

\section{Oxygen uptake and pressure}

Both ACE $\left(0.86 \mathrm{~L} \mathrm{~min}^{-1} \mathrm{~d}=0.68\right)$ and CE $(1.22 \pm 0$. $\left.33 \mathrm{~L} \mathrm{~min}^{-1} \mathrm{~d}=0.76\right) \dot{\mathrm{V}} \mathrm{O}_{2 \text { peak }}$ were significantly greater post-exercise intervention compared to baseline $(p<0$. 01). ACE $\dot{\mathrm{V}} \mathrm{O}_{2 \text { peak }}\left(21.9 \pm 7.1 \mathrm{ml} \mathrm{kg}{ }^{-1} \mathrm{~min}^{-1} \mathrm{~d}=1.09\right)$ improved significantly in comparison to control but not compared to CE group (Table 3).

A tendency to improve was also observed in both $\Delta \mathrm{TcpO} 2(p=0.59, \mathrm{~d}=0.93)$ and transcutaneous oxygen

Table 3 Physiological and quality of life outcomes

\begin{tabular}{|c|c|c|c|c|c|c|}
\hline & \multicolumn{2}{|l|}{$\operatorname{ACE}(n=10)$} & \multicolumn{2}{|l|}{ CE $(n=10)$} & \multicolumn{2}{|c|}{ Control $(n=11)$} \\
\hline & Pre & Post & Pre & Post & Pre & Post \\
\hline ACh CVC & $0.14 \pm 0.06$ & $0.19 \pm 0.08$ & $0.20 \pm 0.11$ & $0.26 \pm 0.1$ & $0.20 \pm 0.08$ & $0.15 \pm 0.08$ \\
\hline $\mathrm{ACh} \mathrm{CVC}_{\max }$ & $1.28 \pm 0.78$ & $1.56 \pm 0.88^{*}$ & $1.49 \pm 0.99$ & $1.26 \pm 0.52$ & $1.40 \pm 0.78$ & $0.82 \pm 0.47$ \\
\hline$A C h T_{\max }(\mathrm{sec})$ & $159.4 \pm 83$ & $104.1 \pm 71.8$ & $172 \pm 57.9$ & $119.4 \pm 82.9$ & $127.9 \pm 51.1$ & $149.9 \pm 70.3$ \\
\hline SNP CVC & $0.15 \pm 0.08$ & $0.24 \pm 0.14$ & $0.21 \pm 0.11$ & $0.25 \pm 0.08$ & $0.20 \pm 0.09$ & $0.20 \pm 0.1$ \\
\hline$S N P C V C_{\max }$ & $1.73 \pm 2.01$ & $1.88 \pm 1.52$ & $1.61 \pm 1.21$ & $2.38 \pm 1.8$ & $1.70 \pm 1.3$ & $1.40 \pm 0.56$ \\
\hline$S N P T_{\max }(\mathrm{sec})$ & $161.2 \pm 88.5$ & $131.3 \pm 77.5$ & $167.4 \pm 66.3$ & $138.8 \pm 80.5$ & $165.5 \pm 56.5$ & $166.9 \pm 76.4$ \\
\hline$\Delta \mathrm{TcpO} 2$ & $2.5 \pm 4.0$ & $9.2 \pm 12.1$ & $1.56 \pm 4.8$ & $1.56 \pm 9.5$ & $1.39 \pm 3.4$ & $0.89 \pm 2.6$ \\
\hline$\Delta \mathrm{T} c p O 2_{\max }$ & $11.5 \pm 3.9$ & $18.4 \pm 16.5$ & $11.7 \pm 3.6$ & $13.6 \pm 9.6$ & $9.44 \pm 7.7$ & $8.0 \pm 7.0$ \\
\hline$\dot{\mathrm{v}} \mathrm{O}_{2 \text { peak }}\left(\mathrm{ml} \mathrm{kg}{ }^{-1} \mathrm{~min}^{-1}\right)$ & $17.7 \pm 4.7$ & $21.9 \pm 7.1^{*}$ & $14.6 \pm 2.9$ & $18.5 \pm 2.8^{*}$ & $14.3 \pm 6.9$ & $14.7 \pm 6.2$ \\
\hline Life satisfaction & $6.5 \pm 1.6$ & $8.1 \pm 1.7^{* * *}$ & $8.4 \pm 1.4^{*}$ & $8.8 \pm 1.1^{* * *}$ & $7.5 \pm 1.6$ & $4.9 \pm 1.5$ \\
\hline Mobility & $2.4 \pm 1.0$ & $2.3 \pm 0.8$ & $1.9 \pm 0.9$ & $1.7 \pm 1.0$ & $1.9 \pm 0.9$ & $2.3 \pm 1.2$ \\
\hline Self-care & $1.1 \pm 0.3$ & $1.1 \pm 0.3$ & $1.2 \pm 0.4$ & $1.0 \pm 0.0$ & $1.4 \pm 0.9$ & $1.7 \pm 1.4$ \\
\hline Usual activity & $2.3 \pm 1.3$ & $1.9 \pm 1.1$ & $1.9 \pm 1.0$ & $1.6 \pm 0.7$ & $1.8 \pm 1.0$ & $2.4 \pm 1.2$ \\
\hline Pain/ discomfort & $2.4 \pm 1.0$ & $2.3 \pm 1.1$ & $2.8 \pm 1.1$ & $1.8 \pm 0.9$ & $2.4 \pm 0.7$ & $2.8 \pm 1.2$ \\
\hline Anxiety/ depression & $1.7 \pm 0.8$ & $1.5 \pm 0.7$ & $1.6 \pm 0.7$ & $1.2 \pm 0.4$ & $1.6 \pm 0.7$ & $1.9 \pm 1.4$ \\
\hline Raynaud's pain & $2.4 \pm 1.4$ & $1.8 \pm 0.6^{*}$ & $2.6 \pm 1.5$ & $1.9 \pm 1.2^{*}$ & $2.4 \pm 0.9$ & $3.1 \pm 1.1$ \\
\hline
\end{tabular}

Endothelial function presented as cutaneous vascular conductance (CVC). $\mathrm{T}_{\max }$ is the time taken to reach peak perfusion. ${ }^{*} p<0.05$ and ${ }^{* * *} p<0.000$ compared to the other groups

$A C E$ arm crank ergometer, SNP sodium nitroprusside, $\triangle T c p \mathrm{O}_{2}$ transcutaneous oxygen tension $\dot{V}_{2 \text { peak }}$ peak oxygen uptake 
tension $\left(\Delta \mathrm{TcpO} 2_{\text {max }}\right)(p=0.71, \mathrm{~d}=0.80)$ in ACE group. Although this improvement is not statistically significant the Cohen's $d$ reveals that the effect size of the change is large (>0.8) both at rest and during provocation (exercise test).

\section{Cutaneous vascular conductance (CVC)}

No statistically significant differences were observed at baseline between the exercise and control groups $(p>0$. $05)$. Post-exercise intervention improvements were observed in the ACE group, especially over the control group, while values in CE group were slightly decreased (Table 3).

\section{Feasibility and tolerance of exercise}

ACE showed to be the mode of exercise that will more likely $(p<0.05)$ engage SSc patients to physical activity twice per week $(6.9 \pm 0.3, d=1.17)$ compared to the $C E$ group $(6.2 \pm 0.79)$. Moreover, ACE demonstrated to be better $(p<0.05)$ regarding participant's confidence to perform two bouts per week $(95 \pm 7 \%, \mathrm{~d}=0.82)$ than $\mathrm{CE}$ $(83 \pm 19.5 \%)$ but not statistically significant. Both exercise modes aggregated a high score of enjoyment levels $>94$ out of 119 with an average effect before, during and after the exercise session of +3 equals to "good".

\section{Quality of life and clinical outcomes}

The EQ-5D-5 L questionnaire did not demonstrate any significant difference between the groups neither at baseline nor after the completion of the exercise intervention, in any of its five elements. However, both exercise groups reported improved life satisfaction $(p<$ $0.000)$ as well as reduced discomfort and pain of Raynaud's phenomenon $(p<0.05)$ after the exercise intervention compared to the control group (Table 3 ). We also reported digital ulcers and hospitalization for iloprost infusion for four out of eleven patients (36.3\%) in the control group. One of them proceeded to amputation of the distal phalange of the middle finger in one hand.

\section{Discussion}

Overall, this study is the first to demonstrate that upperlimb aerobic exercise may be able to improve microvascular endothelial-dependent function in the digital area in patients with systemic sclerosis experiencing
Raynaud's phenomenon. Cycling indicated that it might have the potential to decelerate the disease progression in the vasculature $(\mathrm{ACh})$ as the endothelial-dependent vasodilation was slightly decreased. On the other hand, the control group showed a decrease in endothelialdependent function, which might indicate a disease worsening (Table 3). Pearson's correlation coefficient (Table 4) indicated that the endothelial improvement in $\mathrm{ACE}$ has a trend to correlate with the soft lean and fatfree mass as well as with skeletal muscle mass. Interestingly, ACh showed that is not correlated with ACE $\dot{\mathrm{V}}{ }_{2 \text { peak }}$, which does not confirm to previous findings that have shown association of endothelial-dependent function with the improvement in aerobic capacity in patients with rheumatoid arthritis [30]. The correlation between the endothelial-dependent function and the lean muscle is a vital evidence for future exercise prescription for this population. Resistance training is capable to increase muscle mass and to improve microcirculation in obese adults [31]. Thus a combination of the current HIIT protocol with resistance training might increase the chances for further improvement in the endothelial function.

\section{Endothelial-dependent function}

Our results indicate that exercise training may improve the microvascular function in SSc patients. This could be largely attributed to a shear-stress-related mechanism. Shear stress is a mechanical reaction of the blood vessel to accommodate the increased blood flow, which activates the potassium channels and facilitates the calcium influx into the endothelial cells. Endothelial nitric oxide synthase (eNOS) activation and expression are triggered by an increase in intracellular calcium [32], promoting nitric oxide (NO) production and thus vasodilation [33]. It is possible that the recurring induction of NOS activity with exercise training decelerates the degradation of NO by free radicals in these conditions [34] or by reducing directly free radical production [35]. A recent systematic review on exercise training and vascular function [12] supports our findings indicating that the antioxidant status is enhanced after HIT in patients with cardiometabolic disorders [36-38] and thus, the NO bioavailability is improved. Mitranun et al. [38] assessed the effects of interval aerobic exercise training (three times/week for 12 weeks) on endothelial-

Table 4 Endothelial-dependent correlations in arm cranking

\begin{tabular}{|c|c|c|c|c|c|c|}
\hline & & Soft lean mass $(\mathrm{kg})$ & Fat-free mass (kg) & Skeletal muscle mass (kg) & $\begin{array}{l}\dot{\mathrm{V}} \mathrm{O}_{2 \text { peak }} \\
\left(\mathrm{L} \mathrm{min}^{-1}\right)\end{array}$ & $\begin{array}{l}\dot{\mathrm{V}} \mathrm{O}_{2 \text { peak }} \\
\left(\mathrm{ml} \mathrm{kg}^{-1} \mathrm{~min}^{-1}\right)\end{array}$ \\
\hline \multirow[t]{3}{*}{ ACh $C V C_{\max }$} & Pearson's r & 0.529 & 0.520 & 0.530 & 0.120 & 0.220 \\
\hline & sig (2-tailed) & 0.116 & 0.123 & 0.115 & 0.740 & 0.569 \\
\hline & $n=10$ & 10 & 10 & 10 & 10 & 10 \\
\hline
\end{tabular}

Ach acetylcholine, CVC cutaneous vascular conductance 
dependent vasodilation in patients with type 2 diabetes mellitus. The vascular outcomes demonstrated reductions in erythrocyte malondialdehyde and serum von Willebrand factor and increases in plasma glutathione peroxidase and nitric oxide (all $p<0.05$ ). Therefore, HIIT seems to improve the microvascular function by reducing oxidative stress markers and enhance the antioxidants as well as the vasodilators in cardiometabolic conditions and potentially in connective tissue diseases such as SSc.

\section{Vascular remodelling, shear stress and exercise training}

Evidence for the time course of functional or structural arterial adaptations to exercise training in humans is limited: Short-term effects of exercise improves NO bioavailability, whereas long-term effects induce changes in vascular remodelling [39], an endothelium and NOdependent outcome [40].

Prior to this study, we hypothesised that upper limb exercise would be more effective to improve microcirculation in the local regions compared to lower limb exercise; however, the existing evidence supported systemic effects occur after exercise training in the lower limbs [12]. Therefore, we proceeded to a comparison between the upper and lower limbs. Interestingly, this systemic effect was not proved with our study, where the microvascular reactivity in the digital area was improved with arm cranking but not with cycling. Similar to our findings, Klonizakis et al., [41] reported that arm exercise did not have any impact on lower limbs microcirculation in post-surgical varicose-vein patients. It seems that systemic effects of exercise training can only affect the vascular function in the large arteries (e.g. brachial artery) but not the conduit and resistance arteries. Moreover, the mass of muscle engaged in exercise training could play an important role in the systemic effects as studies that utilized handgrip training have not demonstrated contralateral limb remodelling [42-44]. The explanation probably relies on the magnitude and pattern of shear stress, which in turn triggers the release of $\mathrm{NO}$ and acts as a main determinant for its bioavailability. It is possible that the induced-shear stress by lower limbs is not sufficient to improve the microcirculation in the acral body parts of the upper limbs. Therefore, the volume of blood flow and the magnitude of shear stress induced by HIIT could account for the local effects of exercise training in the smaller arteries $[45,46]$.

\section{Clinical outcome}

Inadequate blood flow to living tissue is often a painful experience, threatening the life of the tissue involved. Digital tissue loss not only results in disfigurement and functional disability, it is also the clinical manifestation of an underlying systemic disease process [47]. One of the direct consequences of digital ischaemia is the persistent digital ulcers developing irreversible tissue loss in $30 \%$ of patients [48]. In our study four out of eleven patients in the control group developed digital ulcers and required hospitalization for iloprost infusion $[49,50]$ for a period of 1 to 3 weeks and one patient proceeded to digital amputation of the distal phalange in the middle finger in one hand. Hospitalization is a psychologically-stressful procedure for the patient, which directly affects QoL. The most common side effects of iloprost infusion could be headache, flushing of the skin, nausea, vomiting and sweating. Amputation has been reported to occur in one or more digits due to ischaemia in $20.4 \%$ of patients with SSc, 9.2\% of which have multiple digit loss [51]. QoL in patients with SSc is adversely affected due to digital ischaemia. Consequently, our protocol has demonstrated that is capable of improving digital ischaemia and preventing disease progression and digital ulcers and thus, improving QoL.

\section{Transcutaneous oxygen pressure}

Although the improvement in oxygen pressure at rest and under provocation (exercise test) was not significant in our study, the effect size of this change was large. This indicates that ACE is able to induce systemic changes in oxygen pressure and vascular function in SSc patients, while the control group showed a slight decrease. It is probable that a higher training load or a larger cohort would have revealed a statistically significant difference between ACE and control group. Evidently, further research is needed to substantiate our findings and explore other training protocols, which will reveal the effects of exercise on skin oxygen pressure, when oxygen demand is higher.

\section{Quality of life}

Both modes of exercise have shown improvement in life satisfaction and reduction in pain or discomfort induced by RP attacks after the exercise training. However, further research is required to confirm the improvement in $\mathrm{RP}$ by applying more qualitative measures (e.g. casespecific questionnaires and face-to-face interviews). Exercise tolerance, cardiorespiratory fitness, walking distance, muscle strength and function as well as healthrelated QoL have been demonstrated to be improved in SSc patients after participation in exercise programmes involving aerobic exercise and aerobic exercise combined with resistance training [52]. Therefore, promoting physical activity for the improvement of QoL in SSc patients should be deemed as one of the priorities for future research.

\section{Feasibility of HIIT}

Our findings demonstrate that HIIT (30 s 100\% PPO/ 30

$\mathrm{s}$ passive recovery) maintained an average effect of +3 
("Good") throughout the exercise training for both modes of exercise. It is also noteworthy that the patient's effect was similar before, during and after the exercise session which could be explained by the moderate cardiorespiratory stress induced by this protocol. Supportive to this finding is the RPE for both groups which averaged to 13 ("Somewhat hard"), a value which is strongly correlated to anaerobic threshold and low to moderate exercise intensity in a large cohort of adults [53]. Exercise intensity and affective response have presented a negative relationship in inactive and overweight adults and it has been reported that as incremental exercise progresses above the ventilatory threshold, the affective response to exercise becomes more negative $[54,55]$. Therefore, a short protocol of HIIT seems to not induce great cardiovascular responses in patients with SSc and that might explain the effect's stability throughout the session.

The intentions regarding engagement to exercise and the task self-efficacy questionnaires as well as the enjoyment levels of the patients could further substantiate whether HIIT is a feasible mode of exercise in SSc patients. Both modes of exercise demonstrated a strong patient's confidence to perform two and three bouts of exercise with arm cranking being slightly higher than cycling. Both modes of exercise were enjoyable for the patients, however, arm cranking was found to be significantly higher in the intentions for engagement in two bouts of exercise per week compared to cycling. HIIT is a feasible protocol to be implemented in patients with SSc and ACE is considered more acceptable than CE potentially, because it is a new mode of exercise for this population and that might increase their interest to perform an alternative type of exercise.

\section{Limitations}

The sample size of the current study could be deemed a limitation for the current study but we need to stress that SSc is not a common condition such as cardiometabolic diseases (e.g. hypertension, obesity, diabetes) and we strictly adhered to the pre-defined eligibility criteria to present a consistent and reproducible outcome. Moreover, the ratio between women and men is uneven, with SSc women to men ratio being estimated to be 5.2:1 in northeast England [56].

$\mathrm{TcpO} 2$ is a direct value of vascular function as changes at rest mimic the changes in arterial $\mathrm{pO}_{2}$ during mild or moderate exercise $[57,58]$. However, the time response of these changes is relatively slow $(90 \%$ time response of TcpO2 being approximately 20 s). Carter and Banham [59] demonstrated that $\mathrm{TcpO} 2$ values closely followed those assessed by direct arterial sampling during cardiopulmonary exercise testing with 2 min intervals. We acknowledge that our protocol utilized $1 \mathrm{~min}$ intervals until symptomatic limitation of exercise, which might affect the accuracy of TcpO2, however, we need to stress that the utilization of TcpO2 measurement in our study was more of a research interest aiming to evaluate the improvement in vascular function after an exercise programme rather than accurately depicting hypoxemia levels in the arterial wall.

Our patients were only of limited cutaneous systemic sclerosis, where the change in skin thickness is little over time compared to diffuse cutaneous systemic sclerosis (Khanna et al., 2017). Moreover, it is common practice in the NHS clinics to assess mRSS only in patients with dcSSc. Therefore, we did not include this measurement in our study; however, we believe that this does not affect our results, as the categorisation of the patients is clear. Also the autoantibody specificities for SSc patients are not included in our study as this is not a standard clinical practice in the area of Sheffield.

\section{Conclusions}

- Aerobic exercise in general, and HIIT (30 s 100\% $\mathrm{PPO} / 30 \mathrm{~s}$ passive recovery) specifically, involving the upper limbs may improve the microvascular reactivity through an enhancement of the endothelial-dependent function. Our results correlated well with the lean muscle mass, which indicates that resistance training could be a complementary training element in inducing further improvements in microcirculation.

- Our protocol appears to reduce digital ischaemia risk, which can be the leading cause for further systemic complications and a major factor affecting the quality of life. Exercise is a non-invasive, adjunct treatment with no adverse effects that is welltolerable by patients with SSc.

- There is a need for large multi-centre, randomisedcontrolled studies to further establish the effects of exercise on SSc patients.

\section{Additional files}

Additional file 1: Feeling scale (SF). (DOCX $38 \mathrm{~kb}$ )

Additional file 2: Exercise task self-efficacy. (DOCX $38 \mathrm{~kb}$ )

Additional file 3: Intentions for engagement to exercise. (DOCX 35 kb)

Additional file 4: Physical activity enjoyment scale. (DOCX 48 kb)

\section{Abbreviations}

6MWT: Six-minute walking test; ACE: Arm crank ergometer; Ach: Acetylcholine; BMI: Body mass index; CE: Cycle ergometer;

CVC: Cutaneous vascular conductance; dcSSc: Diffuse cutaneous scleroderma; eNOS: Endothelial nitric oxide synthase; HIIT: High-intensity interval training; HR: Heart rate; LDF: Laser Doppler fluximetry; ICSSc: Limited cutaneous scleroderma; NO: Nitric oxide; PPO: Peak power output; QoL: Quality of life; RP: Raynaud's phenomenon; RPE: Rating of perceived exertion; SNP: Sodium 
nitroprusside; SSc: Systemic sclerosis; $\dot{V} E$ : Minute ventilation; $\dot{V}_{2 \text { peak: }}$ Peak oxygen uptake; $\mathrm{VT}$ : Tidal volume; $\Delta \mathrm{TcpO}_{2}$ : Transcutaneous oxygen tension

\section{Acknowledgements}

The authors would like to thank the study participants and report no conflicts of interest with this manuscript. The experiments comply with the current UK laws.

\section{Funding}

The work was supported by the Centre for Sports and Exercise Science, Sheffield Hallam University.

\section{Availability of data and materials}

Relevant files of this work will be shared on request.

\section{Authors' contributions}

AM helped to draft the manuscript, designed the exercise intervention, contributed to the study design and critically reviewed and revised the manuscript for important intellectual content. $\mathrm{HC}$ developed the qualitative aspects of the study, contributed to the study design and critically reviewed and revised the manuscript for important intellectual content. GA provided statistical and health economics support, contributed to the study design and critically reviewed and revised the manuscript for important intellectual content. MA is the study's clinical lead, contributed to the study design and critically reviewed and revised the manuscript for important intellectual content. MK is the project leader and helped to draft the manuscript, contributed to the study design and critically reviewed and revised the manuscript for important intellectual content. All authors read and approved the final manuscript for publication.

\section{Ethics approval and consent to participate}

All the patients before their participation to the study were signed informed consent according to the health research authority NHS, UK.

\section{Competing interests}

The authors declare that they have no competing interests.

\section{Publisher's Note}

Springer Nature remains neutral with regard to jurisdictional claims in published maps and institutional affiliations.

\section{Author details}

${ }^{1}$ Centre for Sport and Exercise Science, Collegiate Campus, Sheffield Hallam University, Collegiate Crescent, Sheffield S10 2BP, UK. ${ }^{2}$ Centre for Health and Social Care Research, Sheffield Hallam University, Sheffield, UK.

${ }^{3}$ Rheumatology Department, Royal Hallamshire Hospital, Sheffield, UK.

Received: 2 February 2018 Accepted: 24 April 2018

Published online: 05 June 2018

\section{References}

1. Gabrielli A, Avvedimento EV, Krieg T. Scleroderma. N Engl J Med. 2009;36: 1989-2003.

2. Bolster MBSR. Clinical features of systemic sclerosis. In: Hochberg MC, Silman AJ, Smolen JS, Weinblatt ME, Weisman MH, editors. Rheumatology. 6th ed. Philadelphia: Mosby Elsevier; 2008. p. 1375-85.

3. Jimenez SA, Derk CT. Following the molecular pathways toward an understanding of the pathogenesis of systemic sclerosis. Ann Intern Med. 2004;140:37-50

4. Varga J, Abraham D. Systemic sclerosis: a prototypic multisystem fibrotic disorder. J Clin Invest. 2007;117:557-67.

5. Isenberg DA, Black C. ABC of Rheumatology. Raynaud's phenomenon, scleroderma, and overlap syndromes. BMJ. 1995;310:795-8.

6. Kavian N, Batteux F. Macro- and microvascular disease in systemic sclerosis. Vasc Pharmacol. 2015;71:16-23.

7. Kahaleh B. Progress in research into systemic sclerosis. Lancet. 2004;364: $561-2$.

8. Sunderkötter C, Riemekasten G. Pathophysiology and clinical consequences of Raynaud's phenomenon related to systemic sclerosis. Rheumatology (Oxford). 2006;45:33-5.
9. Altman RD, Medsger TA Jr, Bloch DA, Michel BA. Predictors of survival in systemic sclerosis (scleroderma). Arthritis Rheum. 1991;34:403-13.

10. Pope JE. The diagnosis and treatment of Raynaud's phenomenon: a practical approach. Drugs. 2007;67:517-25.

11. Prescribing \& Medicines Team Health and Social Care Information Centre. Prescription Cost Analysis for England 2015. 2016. https:/digital.nhs.uk/ catalogue/PUB20200. Accessed 07 May 2016.

12. Ramos JS, Dalleck LC, Tjonna AE, Beetham KS, Coombes JS. The impact of high-intensity interval training versus moderate-intensity continuous training on vascular function: a systematic review and meta-analysis. Sports Med. 2015:45:679-92.

13. Meyer P, Normandin E, Gayda M, Billon G, Guiraud T, Bosquet L, et al. Highintensity interval exercise in chronic heart failure: protocol optimization. J Card Fail. 2012;18:126-33.

14. Smith-Ryan A. Enjoyment of high-intensity interval training in an overweight/ obese cohort: a short report. Clin Physiol Funct Imaging. 2017;37:89-93.

15. Guiraud T, Nigam A, Gremeaux V, Meyer P, Juneau M, Bosquet L. High-intensity interval training in cardiac rehabilitation. Sports Med. 2012;42:587-605.

16. Kessler HS, Sisson SB, Short KR. The potential for high-intensity interval training to reduce cardiometabolic disease risk. Sports Med. 2012;42:489-509.

17. Hoogen F, Khanna D, Fransen J, Johnson SR, Baron M, Tyndall A, et al. 2013 Classification Criteria for Systemic Sclerosis: An American College of Rheumatology/European League Against Rheumatism Collaborative Initiative. Arthritis Rheum. 2013;65:2737-47.

18. Borg GA. Perceived exertion: a note on "history" and methods. Med Sci Sports. 1973;5:90-3.

19. Smith PM, Price MJ, Doherty M. The influence of crank rate on peak oxygen consumption during arm crank ergometry. J Sports Sci. 2001;19:955-60.

20. Smith PM, Doherty M, Price MJ. The effect of crank rate strategy on peak aerobic power and peak physiological responses during arm crank ergometry. J Sports Sci. 2007;25:711-8.

21. Wasserman K. In: Hansen JE, Sue DY, Stringer WW, Sietsema KE, Sun XG, Whipp BJ, editors. Principles of exercise testing and interpretation: including pathophysiology and clinical applications. London: Wolters Kluwer/Lippincott Williams \& Wilkins; 2012. p. 141-2.

22. Deuschle K, Weinert K, Becker MO, Backhaus M, Huscher D, Riemekasten G. Six-minute walk distance as a marker for disability and complaints in patients with systemic sclerosis. Clin Exp Rheumatol. 2011;29:S53-9.

23. Klonizakis M, Tew G, Michaels J, Saxton J. Exercise training improves cutaneous microvascular endothelial function in post- surgical varicose vein patients. Microvasc Res. 2009;78:67-70.

24. Klonizakis M, Tew G, Michaels J, Saxton J. Impaired microvascular endothelial function is restored by acute lower-limb exercise in postsurgical varicose vein patients. Microvasc Res. 2009;77:158-62.

25. Wasilewski R, Ubara EO, Klonizakis M. Assessing the effects of a short-term green tea intervention in skin microvascular function and oxygen tension in older and younger adults. Microvasc Res. 2016;107:65-71.

26. Dolan P. Modeling valuations for EuroQol health states. Med Care. 1997;35: 1095-108.

27. Jung ME, Bourne JE, Little JP. Where does HIT fit? An examination of the affective response to high-intensity intervals in comparison to continuous moderate- and continuous vigorous-intensity exercise in the exercise intensity-affect continuum. PLoS One. 2014;9:e114541.

28. Mullineaux DR, Bartlett RM, Bennett $S$. Research design and statistics in biomechanics and motor control. J Sports Sci. 2001:19:739-60.

29. Mitropoulos A, Gumber A, Crank H, Klonizakis M. Validation of an arm crank ergometer test for use in sedentary adults. J Sports Sci Med. 2017;16:558-64.

30. Metsios GS, Stavropoulos-Kalinoglou A, Veldhuijzen vZ, Nightingale P, Sandoo A, Dimitroulas T, et al. Individualised exercise improves endothelial function in patients with rheumatoid arthritis. Ann Rheum Dis. 2014;73:748.

31. Dias I, Farinatti P, De Souza MG, Manhanini DP, Balthazar E, Dantas DL, et al. Effects of resistance training on obese adolescents. Med Sci Sports Exerc. 2015;47:2636-44.

32. Laughlin M, Newcomer S, Bender S. Importance of hemodynamic forces as signals for exercise-induced changes in endothelial cell phenotype. J Appl Physiol. 2008;104:588.

33. Busse R, Mülsch A. Induction of nitric oxide synthase by cytokines in vascular smooth muscle cells. FEBS Lett. 1990;275:87-90.

34. Fukai T, Siegfried MR, Ushio-Fukai M, Cheng Y, Kojda G, Harrison DG. Regulation of the vascular extracellular superoxide dismutase by nitric oxide and exercise training. J Clin Invest. 2000;105:1631. 
35. Adams V, Linke A, Krankel N, Erbs S, Gummert J, Mohr F, et al. Impact of regular physical activity on the expression of angiotensin II receptors and activity of NADPH oxidase in the left mammarial artery of patients with coronary artery disease. Eur Heart J. 2004;25:224.

36. Wisloff PU, Stoylen MA, Loennechen EJ, Bruvold AM, Rognmo JO, Haram LP, et al. Superior cardiovascular effect of aerobic interval-training versus moderate continuous training in elderly heart failure patients. Med Sc Sports Exerc. 2007;39:S32.

37. Tjønna AE, Lee SJ, Rognmo Ø, Stølen TO, Bye A, Haram PM, et al. Aerobic interval training versus continuous moderate exercise as a treatment for the metabolic syndrome: a pilot study. Circulation. 2008;118:346-54.

38. Mitranun W, Deerochanawong C, Tanaka H, Suksom D. Continuous vs interval training on glycemic control and macro- and microvascular reactivity in type 2 diabetic patients. Scand J Med Sci Sports. 2014;24:e69-76.

39. Laughlin MH, Rubin LJ, Rush JW, Price EM, Schrage WG, Woodman CR. Short-term training enhances endothelium-dependent dilation of coronary arteries, not arterioles. J Appl Physiol. 2003;94:234Y44.

40. Tronc F, Wassef M, Esposito B, Henrion D, Glagov S, Tedgui A. Role of NO in flow-induced remodeling of the rabbit common carotid artery. Arterioscler Thromb Vasc Biol. 1996;16:1256-62.

41. Klonizakis M, Winter E. Effects of arm-cranking exercise in cutaneous microcirculation in older, sedentary people. Microvasc Res. 2011;81:331-6.

42. Sinoway LI, Musch TI, Minotti JR, Zelis R. Enhanced maximal metabolic vasodilatation in the dominant forearms of tennis players. J Appl Physiol (1985). 1986;61:673-8.

43. Green DJ, Cable NT, Fox C, Rankin JM, Taylor RR. Modification of forearm resistance vessels by exercise training in young men. J Appl Physiol (Bethesda, MD: 1985). 1994;77:1829.

44. Green DJ, Fowler DT, O'Driscoll JG, Blanksby BA, Taylor RR. Endotheliumderived nitric oxide activity in forearm vessels of tennis players. J Appl Physiol (Bethesda, MD.: 1985). 1996;81:943.

45. Ribeiro F, Alves AJ, Duarte JA, Oliveira J. Is exercise training an effective therapy targeting endothelial dysfunction and vascular wall inflammation? Int J Cardiol. 2010;141:214-21.

46. Liu L, Yu B, Chen J, Tang Z, Zong C, Shen D, et al. Different effects of intermittent and continuous fluid shear stresses on osteogenic differentiation of human mesenchymal stem cells. Biomech Model Mechanobiol. 2012;11:391-401.

47. Mcmahan Z, Wigley F. Raynaud's phenomenon and digital ischemia: a practical approach to risk stratification, diagnosis and management. Int J Clin Rheumatol. 2010;5:355-70.

48. Ingraham KM, Steen VD. Morbidity of digital tip ulcerations in scleroderma. Arth Rheum. 2006;54:P578.

49. Vitielo M, Abuchar A, Santana N, Dehesa L, Kerdel FA. An update on the treatment of the cutaneous manifestations of systemic sclerosis: The dermatologist's point of view. J Clin Aesthet Dermatol. 2012;5:33-43.

50. Pope J, Fenlon D, Thompson A, Shea B, Furst D, Wells GA, et al. Iloprost and cisaprost for Raynaud's phenomenon in progressive systemic sclerosis. Cochrane Database Syst Rev. 2000;2:CD000953.

51. Wigley FM, Wise RA, Miller R, Needleman BW, Spence RJ. Anticentromere antibody as a predictor of digital ischemic loss in patients with systemic sclerosis. Arthritis Rheum. 1992;35:688-93.

52. Oliveira NC, Portes LA, Pettersson H, Alexanderson H, Boström C. Aerobic and resistance exercise in systemic sclerosis: state of the art. Musculoskeletal Care. 2017;15:316-23.

53. Scherr J, Wolfarth B, Christle JW, Pressler A, Wagenpfeil S, Halle M. Associations between Borg's rating of perceived exertion and physiological measures of exercise intensity. Eur J Appl Physiol. 2013;113:147-55.

54. Blanchard CM, Rodgers WM, Spence JC, Courneya KS. Feeling state responses to acute exercise of high and low intensity. J Sci Med Sport. 2001:4:30-8.

55. Parfitt G, Hughes S. The exercise intensity-affect relationship: evidence and implications for exercise behavior. J Exerc Sci Fit. 2009;7:S34-41.

56. Allcock RJ, Forrest I, Corris PA, Crook PR, Griffiths ID. A study of the prevalence of systemic sclerosis in northeast England. Rheumatology (Oxford). 2004;43:596-602.

57. Brudin L, Berg S, Ekberg P, Castenfors J. Is transcutaneous PO2 monitoring during exercise a reliable alternative to arterial PO2 measurements? Clin Physiol. 1994;14:47-52.
58. Planès $C$, Leroy $M$, Foray $E$, Raffestin $B$. Arterial blood gases during exercise: validity of transcutaneous measurements. Arch Phys Med Rehabil. 2001;82: 1686-91.

59. Carter R, Banham SW. Use of transcutaneous oxygen and carbon dioxide tensions for assessing indices of gas exchange during exercise testing. Respir Med. 2000;94:350-5.

\section{Ready to submit your research? Choose BMC and benefit from:}

- fast, convenient online submission

- thorough peer review by experienced researchers in your field

- rapid publication on acceptance

- support for research data, including large and complex data types

- gold Open Access which fosters wider collaboration and increased citations

- maximum visibility for your research: over $100 \mathrm{M}$ website views per year

At BMC, research is always in progress.

Learn more biomedcentral.com/submissions 